\title{
Awareness of traumatic occult lateral mass fracture of the cervical spine triggered by the presence of unilateral vertebral artery occlusion: a case report
}

\author{
Tsunehiko Konomi $\mathbb{D}^{1,2} \cdot$ Kota Suda $^{1} \cdot$ Satoko Matsumoto ${ }^{1} \cdot$ Miki Komatsu $^{1} \cdot$ Masahiko Takahata $^{3} \cdot$ \\ Norimasa Iwasaki ${ }^{3} \cdot$ Akio Minami $^{1}$
}

Received: 4 October 2017 / Revised: 13 February 2018 / Accepted: 15 February 2018

(c) International Spinal Cord Society 2018

\begin{abstract}
Introduction We present an unusual case of traumatic occult lateral mass fracture of the cervical spine with unilateral occlusion of the vertebral artery (VA), that was missed by plain X-ray and magnetic resonance imaging (MRI), but identified by computed tomography (CT) after suspecting high-energy trauma as the underlying cause.

Case presentation A 67-year-old male was injured in a car accident and came to our institute on foot 4 days after injury with complaints of neck pain and numbness in the right hand. Although, no specific bone injury was visible on plain X-ray, the absence of flow voids in the right VA was confirmed on axial T2-weighted MRI. We suspected high-energy trauma of the cervical spine at that point and performed CT for a more detailed assessment. Consequently, a fracture was detected in the right lateral mass of $\mathrm{C} 6$ and we speculated that spontaneous reduction of the fracture-dislocation had occurred. One-stage surgery with posterior fixation was subsequently performed for instability. The patient's preoperative symptoms were improved and neither recanalization of the occlusion nor another VA occlusion was observed after surgery.

Discussion VA injury occurs frequently as a complication of blunt cervical spine trauma. In the present case, however, the lateral mass fracture was not seen on MRI and missed until the unilateral VA injury was detected. When high-energy trauma of the cervical spine is suspected, it is important to evaluate damage to the spinal cord, bone, soft-tissue, and VA by MRI and CT.
\end{abstract}

\section{Introduction}

Fracture of the cervical spine is often missed by plain X-ray. Therefore, we use magnetic resonance imaging (MRI) to investigate damage to the spinal cord, bone, and soft-tissue. Here, however, we describe a rare case of occult lateral mass fracture with unilateral occlusion of the vertebral artery (VA) that was not recognized by plain X-ray or MRI.

Tsunehiko Konomi

konomitsunehiko@gmail.com

1 Department of Orthopedic Surgery, Hokkaido Spinal Cord Injury Center, 3-1 Higashi-4 Minami-1, Bibai, Hokkaido 072-0015, Japan

2 Department of Orthopedic Surgery, Murayama Medical Center, National Hospital Organization, 2-37-1 Gakuen, Musashimurayama, Tokyo 208-0011, Japan

3 Department of Orthopedic Surgery, Graduate School of Medicine, Hokkaido University, Kita 8, Nishi 5, Kita-ku, Sapporo, Hokkaido 060-0808, Japan
This case highlights the importance of evaluating the cervical spine by both MRI and computed tomography (CT), when suspecting high-energy trauma as the underlying cause.

\section{Case presentation}

The patient was a 67-year-old male who had previously been healthy and had no appreciable disease in the past except for lumber spinal canal stenosis. He came to the outpatient department of our institute on foot with complaints of neck pain and numbness in the right hand since a traffic accident in which his car was overturned 4 days earlier.

At the initial visit, the patient's cervical spine was limited in self-motion because of pain. Numbness was present at the C6 dermatome in his right arm and slight muscle weakness (manual muscle testing grade 3 ) was observed during dorsiflexion of the right hand. No other neurological deficit was observed. Although, no fractures were visible on plain $\mathrm{X}$ - 


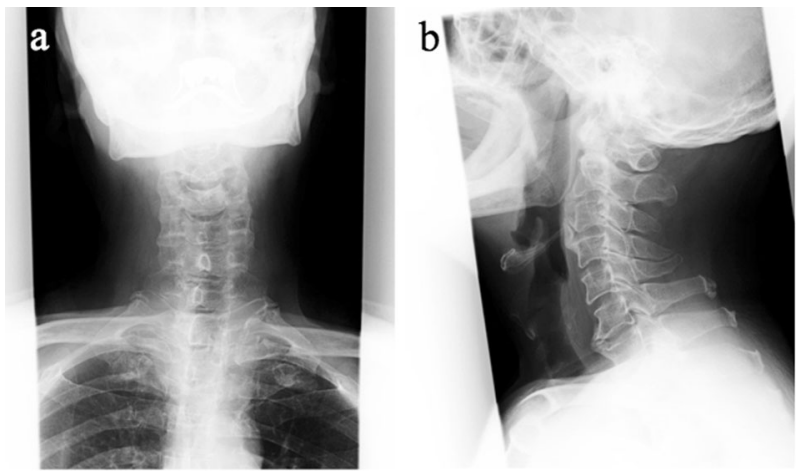

Fig. 1 Plain X-ray of the cervical spine (a front view, $\mathbf{b}$ lateral view) at the initial visit showed no specific bone injury
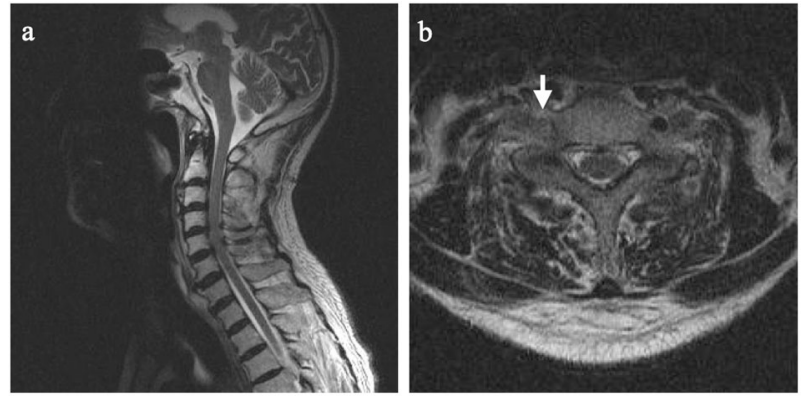

Fig. 2 T2-weighted MRI of the cervical spine (a sagittal view, b axial view of C5). The absence of flow voids in the right VA (white arrow) was confirmed on the axial view

ray of the cervical spine (Fig. 1), MRI was performed due to $\mathrm{C} 6$ radicular signs. Consequently, the absence of flow voids in the right foramen transversarium was confirmed on axial T2-weighted images and VA occlusion was suspected (Fig. 2). Neither spinal dural canal compression nor soft-tissue damage, nor fracture was observed on axial and parasagittal view. At that point, we performed CT of the cervical spine for a more detailed assessment. A fracture was detected at the right lateral mass of $\mathrm{C} 6$ and on $\mathrm{CT}$ and MR angiography, complete occlusion of the right VA was confirmed (Fig. 3). Collectively, the patient was diagnosed with spontaneous reduction of a fracture-dislocation of the cervical spine associated with right VA occlusion and C6 nerve damage and we proceeded to surgical treatment 2 days after the initial visit.

One-stage surgery was performed with a posterior approach using C5/6 lateral mass screws on the left and wire between the spinous processes for posterior fixation. Severe instability was observed at the C5/6 level. An autogenous bone graft was placed at the right intervertebral joint. Surgery was performed without any complications (time of operation: $80 \mathrm{~min}$; estimated blood loss: $10 \mathrm{~mL}$ ). Postoperatively, a cervical hard collar (Bi-Turnbuckle Ortho collar; K.K Arizono Seisakusho, Kitakyushu, Japan [1]) was applied to stabilize the cervical spine. On MR angiography, neither recanalization of the VA nor another VA occlusion was observed. The patient's preoperative symptoms and muscle weakness improved and bony fusion was confirmed. The patient resulted in his daily life without any specific problems.

\section{Discussion}

VA injury occurs frequently as a complication of blunt cervical spine trauma. In general, VA injury accounts for $17-46 \%$ of all blunt cervical spine traumas, and $0-45 \%$ of VA injury is associated with brain infarction, which leads to death $0-18 \%$ [2-9]. It is also understood that trauma associated with fracture of the transversarium, facet fracture-dislocation, or vertebral subluxation of the cervical spine is highly likely to lead to VA injury [10]. VA occlusion is more common in motor-complete patients than in motor-incomplete or neurologically intact cervical spine injured patients. However, Torina et al. [11] concluded that the absence of neurologic symptoms in a patient with cervical spine fracture does not preclude VA occlusion and recommended that MR angiography should be considered in the diagnostic evaluation of these patients.

MRI is often superior to CT scan for detection of neural, ligamentous, and disc injuries and is seen as a gold standard by certain authors for clearing the cervical spine in a clinically suspicious or unevaluatable blunt trauma patients [12-14]. Muchow et al. [13] reported MRI could provide objective findings about the injury with a $100 \%$ negative predictive value. In contrast, the incidence of cervical spine bone injury that cannot be detected by plain X-ray alone accounts for as much as $18-53 \%$ of cases [15-18]. Some studies have suggested that a cervical CT scan is useful and should replace cervical spine radiographs for the initial evaluation of blunt cervical spine injury so as not to miss an occult bone injury [19-22]. The early detection of a cervical spine bone injury could be possible at the emergency units of medical centers wherein patients with high-energy trauma are transferred, since a whole-body CT scan is recommended [21, 23]. However, a whole-body CT scan is not necessary for all patients with a neck pain, as in the present case who attended the hospital by himself on the 4th post-injury day. In addition, MRI is often prioritized after plain X-ray when obstruction of the spinal cord is suspected to avoid exposing patients to unnecessary radiation and harm. In the present case, however, the lateral mass fracture was MRI-negative. Furthermore, neither specific soft-tissue damage nor a severe neurological deficit, except C6 spinal nerve radiculopathy, was observed. Awareness of traumatic occult lateral mass fracture of the cervical spine triggered by the presence of unilateral VA occlusion and a prediction of high-energy trauma as the underlying cause like our case are unusual and rarely described. 
Fig. 3 Fracture of the right lateral mass of C6 was observed on axial CT (a) of the cervical spine (white arrow). CT (b) and MR (c) angiography showed complete occlusion of the right VA (black arrow)
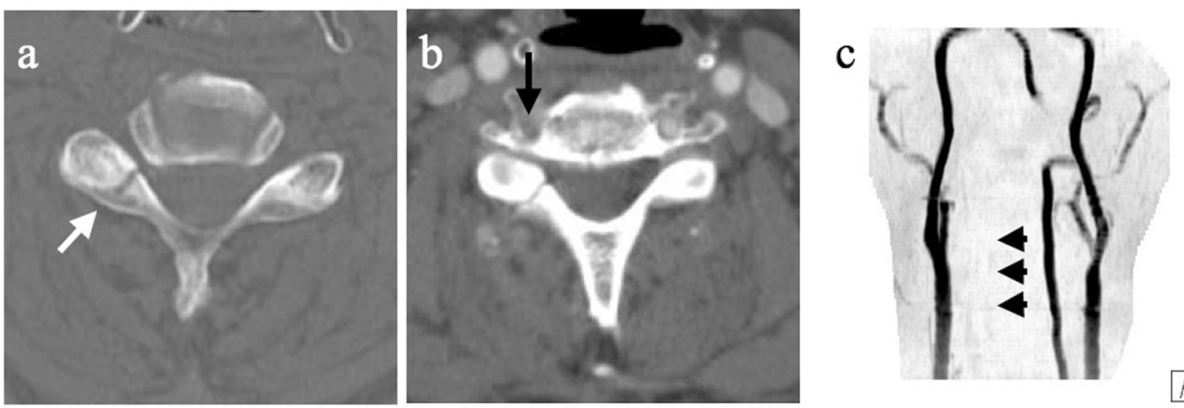

On the basis of traumatic force and the presence of a lateral mass fracture ipsilateral to the VA occlusion, it could be speculated that a spontaneous reduction of the fracturedislocation, which is classified as a compressive-extension injury with rotatory force, had occurred [24]. Posterior fixation and bone fusion were performed to treat the rotatory instability. No antithrombotic treatment was performed for the VA occlusion because of the potential risk for increased bleeding during surgery. There is controversy in the treatment of blunt VA occlusion between the use of embolization and antithrombotic therapy regarding the benefits gained by blood flow and the risk of developing a reperfusion disorder [10, 25, 26]. Furthermore, we previously experienced the occurrence of delayed secondary bilateral VA occlusion after inadequate management of traumatic cervical spine injury [20]. In that case, interestingly, appropriate surgical reduction and stabilization restored the unilateral occlusion. In the present case, neither recanalization nor another occlusion of the VA was observed even after surgery, and no sign of brain infarction has been observed until the present time, which might be due to the early stabilization of the fracture.

In conclusion, this report describes a rare case of MRInegative traumatic occult lateral mass fracture of the cervical spine with unilateral VA occlusion. It is important to perform both MRI and CT when high-energy trauma of cervical spine is suspected, taking into consideration damage to bone, soft tissue, and the VA. Furthermore, early stabilization of an unstable cervical spine fracture is also necessary for the prevention of secondary VA occlusion.

\section{Compliance with ethical standards}

Conflict of interest The authors declare that they have no conflict of interest.

\section{References}

1. Nagata K, Takamatsu T, Matsuyama M, Kamo K, Inoue A, Arizono S. New cervical orthosis effect on cervical spine motion. Orthop Traumatol. 1989;37:1800-4. (Japanese)
2. Desouza RM, Crocker MJ, Haliasos N, Rennie A, Saxena A. Blunt traumatic vertebral artery injury: a clinical review. Eur Spine J. 2011;20:1405-16.

3. Fassett DR, Dailey AT, Vaccaro AR. Vertebral artery injuries associated with cervical spine injuries: a review of the literature. J Spinal Disord Tech. 2008;21:252-8.

4. Friedman D, Flanders A, Thomas C, Millar W. Vertebral artery injury after acute cervical spine trauma: rate of occurrence as detected by MR angiography and assessment of clinical consequences. AJR Am J Roentgenol. 1995;164:443-9.

5. Giacobetti FB, Vaccaro AR, Bos-Giacobetti MA, Deeley DM, Albert TJ, Farmer JC, et al. Vertebral artery occlusion associated with cervical spine trauma. A prospective analysis. Spine. 1997;22:188-92.

6. Louw JA, Mafoyane NA, Small B, Neser CP. Occlusion of the vertebral artery in cervical spine dislocations. J Bone Jt Surg Br. 1990;72:679-81.

7. Taneichi H, Suda K, Kajino T, Kaneda K. Traumatically induced vertebral artery occlusion associated with cervical spine injuries: prospective study using magnetic resonance angiography. Spine. 2005;30:1955-62.

8. Willis BK, Greiner F, Orrison WW, Benzel EC. The incidence of vertebral artery injury after midcervical spine fracture or subluxation. Neurosurgery. 1994;34:435-42.

9. Woodring JH, Lee C, Duncan V. Transverse process fractures of the cervical vertebrae: are they insignificant? J Trauma. 1993;34:797-802.

10. Harrigan MR, Hadley MN, Dhall SS, Walters BC, Aarabi B, Gelb DE. et al. Management of vertebral artery injuries following nonpenetrating cervical trauma. Neurosurgery. 2013;72(Suppl 2):234-43.

11. Torina PJ, Flanders AE, Carrino JA, Burns AS, Friedman DP, Harrop JS, et al. Incidence of vertebral artery thrombosis in cervical spine trauma: correlation with severity of spinal cord injury. Am J Neuroradiol. 2005;26:2645-51.

12. Pourtaheri S, Emami A, Sinha K, Faloon M, Hwang K, Shafa E, et al. The role of magnetic resonance imaging in acute cervical spine fractures. Spine J. 2014;14:2546-53.

13. Muchow RD, Resnick DK, Abdel MP, Munoz A, Anderson PA. Magnetic resonance imaging (MRI) in the clearance of the cervical spine in blunt trauma: a meta-analysis. J Trauma. 2008;64:179-89.

14. Schoenfeld AJ, Bono CM, McGuire KJ, Warholic N, Harris MB. Computed tomography alone versus computed tomography and magnetic resonance imaging in the identification of occult injuries to the cervical spine: a meta-analysis. J Trauma. 2010;68:109-14.

15. Williams CF, Bernstein TW, Jelenko C 3rd. Essentiality of the lateral cervical spine radiograph. Ann Emerg Med. 1981;10:198-204.

16. Walter J, Doris PE, Shaffer MA. Clinical presentation of patients with acute cervical spine injury. Ann Emerg Med. 1984;13:512-5. 
17. Roth BJ, Martin RR, Foley K, Barcia PJ, Kennedy P. Roentgenographic evaluation of the cervical spine. A selective approach. Arch Surg. 1994;129:643-5.

18. Lin JT, Lee JL, Lee ST. Evaluation of occult cervical spine fractures on radiographs and CT. Emerg Radiol. 2003;10:128-34.

19. Bailitz J, Starr F, Beecroft M, Bankoff J, Roberts R, Bokhari F, et al. CT should replace three-view radiographs as the initial screening test in patients at high, moderate, and low risk for blunt cervical spine injury: a prospective comparison. J Trauma. 2009;66:1605-9.

20. Kirshenbaum KJ, Nadimpalli SR, Fantus R, Cavallino RP. Unsuspected upper cervical spine fractures associated with significant head trauma: role of CT. J Emerg Med. 1990;8:183-98.

21. Imerci A, Canbek U, Kaya A, Surer L, Savran A. Distribution of occult fractures detected in emergency orthopedic patient trauma with computerized tomography. Ulus Travma Acids Cerrah Derg. 2013;19:157-63.

22. Ghaffarpasand F, Paydar S, Foroughi M, Saberi A, Abbasi H, Karimi AA, et al. Role of cervical spine radiography in the initial evaluation of stable high-energy blunt trauma patients. J Orthop Sci. 2011;16:498-502.

23. Berne JD, Velmahos GC, El-Tawil Q, Demetriades D, Asensio JA, Murray JA, et al. Value of complete cervical helical computed tomographic scanning in identifying cervical spine injury in the unevaluable blunt trauma patient with multiple injuries: a prospective study. J Trauma. 1999;47:896-903.

24. Allen BL Jr., Ferguson RL, Lehmann TR, O'Brien RP. A mechanistic classification of closed, indirect fractures and dislocations of the lower cervical spine. Spine. 1982;7:1-27.

25. Nakao Y, Terai H. Distal embolic brain infarction due to recanalization of asymptomatic vertebral artery occlusion resulting from cervical spine injury: a case report. J Chiropr Med. 2014;13:266-72.

26. Komatsu M, Suda K, Takahata M, Matsumoto S, Ushiku C, Yamada K, et al. Delayed bilateral vertebral artery occlusion after cervical spine injury: a case report. Spinal Cord Ser Cases. 2016;2:16031. 